\title{
Comparative Study of Rapid DNA Extraction Methods of Pathogenic Bacteria
}

\author{
Mandour H. Abdelhai ${ }^{1}$, Hinawi A. M. Hassanin ${ }^{2}$, Xiulan Sun ${ }^{1}$ \\ ${ }^{1}$ State Key Laboratory of Food Science and Technology, School of Food Science and Technology, Synergetic Innovation Center of Food \\ Safety and Nutrition, Wuxi, Jiangsu, China \\ ${ }^{2}$ State Key Laboratory of Food Science and Technology, School of Food Science and Technology, Wuxi, Jiangsu, China
}

Email address:

sxlzzz@jiangnan.edu.cn (Xiulan Sun), mabdalhai1@hotmail.com (M. H. Abdelhai)

\section{To cite this article:}

Mandour H. Abdelhai Hinawi, A. M. Hassanin, Xiulan Sun. Comparative Study of Rapid DNA Extraction Methods of Pathogenic Bacteria. American Journal of Bioscience and Bioengineering. Vol. 4, No. 1, 2016, pp. 1-8. doi: 10.11648/j.bio.20160401.11

\begin{abstract}
Detection of pathogenic bacteria in food is most important for food safety and quality control, and the critical step it chooses the rapid, sensitive and more economical method to extract DNA to produce high quality and decrease the timeconsuming of measuring. Extraction of nucleic acids is the first step in most molecular biology studies and in all recombinant DNA techniques, but the difficult access steps and critical of analysis. Here we report, describe and compare the simple and fast methods of extraction (physical, boiling, phenol/ethanol and commercial kit) methods, from pure culture and then from beef samples. The quantity and quality of extraction methods were confirmed by polymerase chain reaction, agarose gel electrophoresis, and spectrophotometer nanodrop. Results revealed that the efficiently for all three methods were significant compared with the commercial kit, however, in pure culture the boiling method sex tract its more efficient, convenient and cheaper method for template preparation and significant when it compare with other methods while in beef samples experimental results showed that the phenol/ethanol method extract its more significantly.
\end{abstract}

Keywords: DNA Extraction, Food Safety, Polymerase Chain Reaction, Pathogenic Bacteria

\section{Introduction}

Escherichia coli O157:H7 (designated by its somatic, O, and flagellar, $\mathrm{H}$, antigens) was first recognized as a human pathogen following two hemorrhagic colitis outbreaks in 1982. E. coli serotype O157:H7 is a rare variety of $E$. coli but is a normal inhabitant of the intestines of all animals, including humans. The pathogen produces large quantities of one or more related potent toxins, called Shiga toxins, which cause severe damage to the lining of the intestine and to other target organs, The most severe outcome of Shiga toxin exposure among the general population is typically hemorrhagic colitis, a prominent symptom of which is bloody [1]. Staphylococcus aureus is also an important hazard from a food safety perspective as it is able to produce staphylococcal enterotoxins, preformed in food. As one of the most common pathogenic bacteria in food, S. aureus was hard to eliminate from human environment and resulted in many cases of food poisoning by yielding staphylococcal enterotoxins in many countries, also its an important hazard from a food safety perspective as it is able to produce staphylococcal enterotoxins [2]. Aeromonas hydrophila is characterized to cause disease both for cold-blooded and warm-blooded animal is an important pathogen that causes disease to animals and human [3]. A. hydrophila is frequently involved in human and animal infections acting as opportunistic or primary pathogen. Human infections range from gastroenteritis to extra-intestinal diseases. The wide distribution of $A$. hydrophila in different habitats probably reflects its adaptability to different environmental conditions [4]. Different environmental sources of Salmonella spp. include soil, water, insect, factory, human and animal faeces, raw poultry eggs, etc [5]. Salmonella spp. has been associated with fecal contamination, and it's a most important cause of human pathogens. It causes gastroenteritis and is a leading cause of food related deaths. Annually in the United States salmonellosis is estimated to sicken 1 million people resulting in approximately 19,000 hospitalizations and 378 deaths $[6,7]$. Salmonella spp. species are Gram-negative, non spore forming bacteria, flagellated bacteria. Salmonella spp. genus includes two species (Salmonella spp. enterica and Salmonella spp. bongori), seven subgroups and more 
than 2,500 serovars. All can cause human diseases, such as typhoid fever, paratyphoid fever, food poisoning and other salmonellosis [8,9]. Salmonella is found worldwide in both cold-blooded and warm-blooded animals, and in the environment.

DNA is a polymer made of nucleotide monomers, Deoxyribionuclic acid (DNA) contain unique genetic information (genetic sequences information) for every human being and livening organism president in the earth, when obtaining DNA sequences data, small errors in this information could results in large mistake in identification. It most commonly exists as a double-stranded macromolecule where two polynucleotide strands are held together by hydrogen bonds between the complementary nitrogenous bases. DNA as a double stranded helix formation of sugar phosphates connected together by four base elements, or nucleotides. Those four base elements are Adenine (A) cytosine $(\mathrm{C})$, guanine $(\mathrm{G})$ and thymine $(\mathrm{T})$. Unique condition of DNA bonded paire is that the pair adenine and thymine will only bond with each other's [10]. The breakdown of cells can be achieved by either mechanical methods, such as grinding with mortar and pestle, or a chemical method that lyses cells by disrupting cell membranes. The order of the bases determines the proteins, the cell makes and the functions the cell reforms. Numerous quick DNA isolation methods have been established to promote large-scale genomic applications during the past years [11]. As a wide variety of methods exist for extraction of nucleic acids, the choice of the most suitable technique is generally based on the criteria: target nucleic acid, source organism, starting material (tissue, leaf, seed, processed material, etc.), desired results (yield, purity, purification time required, etc.) and downstream application (PCR, cloning, labeling, blotting, RT-PCR, DNA synthesis, etc.).

The first step of extraction DNA from biological material requires the rupture of the cell lysis and nucleus wall, inactivation of cellular nucleases and separation of the desired nucleic acid from cellular debris. Often, the ideal lysis procedure is a compromise of techniques and must be rigorous enough to disrupt the complex starting material (e.g. tissue). Common lysis procedures include mechanical disruption (e.g. grinding, hypotonic lysis), Chemical treatment (e.g. detergent lysis, chaotropic agents, thiol reduction) and Enzymatic digestion (e.g. proteinase K) [12]. All biological membranes have a common overall structure comprising lipid and protein molecules held together by noncovalent interactions whereas the bottleneck has been the genotyping technology and price, it has now become the accessibility of samples [13]. However, the extraction of genomic DNA bacteria from real food material is often difficult. Differences in cell wall structure and in adhesion properties of microorganisms together with physical, chemical and biological food characteristics affect this extraction. Figure 1 shows the difference between gram negative and positive. Many methods of extracting bacterial DNA directly from the crushed mother solution, including rapid methods and commercial kits, have been compared $[14,15]$.
Polymerase chain reaction is the most commonly used analytical methods in genetics and molecular biology and it is important methods introduced in food microbiology. Many established PCR-based approaches in molecular biology rely on lengthy and expensive methods for isolation of nucleic acids. Although several rapid DNA extraction protocols are available, they more complicate and expensive and need high experience to use because the methods of extraction effect on efficiency of PCR also the residue of material used in extraction. To overcome the disadvantages of culturedependent methods, the use of PCR to detect bacteria in food has been developed in recent years. However, the extraction of bacterial DNA from heterogeneous food material is often a hurdle. Differences in cell wall structure and in adhesion properties of microorganisms together with physical chemical and biological food characteristics affect this extraction. [16]. In this study, we determine the highly efficient, convenient and lower-cost to extract high quality of genomic DNA and comparison between the different methods of extraction. The efficiency of a high quality DNA of each one to obtain highly extract DNA from real samples to choose the suitable extraction methods then should be applied to PCR to use the target DNA in further experiments like DGGE, RT-PCR, electrochemical biosensor and etc.

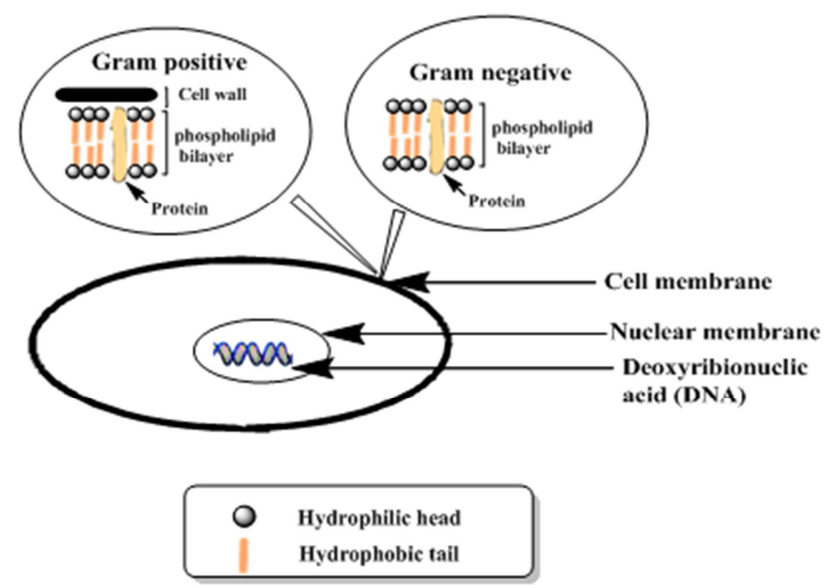

Figure 1. Diagram of different cell membrane structure between gram negative and positive bacteria.

\section{Materials and Methods}

\subsection{Strains, Cultivation and Extraction DNA}

Pathogenic bacteria: $S$. aureus (Accession number EF520720.1), A. hydrophila (Accession number, M84709), E. coli 0157:H7 (Accession number JX206444.1) and Salmonella enterica (Accession number GU390666) was used as target. All bacterial strains were obtained from the (Zhangjiagang Entry-Exit Inspection and Quarantine Bureau, Suzhou, Jiangsu province, China), (Freshwater Fisheries Research Center, Wuxi, China) and Jiangnan university laboratory. The nucleotide sequences submitted with these accession numbers were employed in designing primers for targeted gene amplification in previous work except 
salmonella we design in this work. A. hydrophila was growing in Ampicilin starch agar phenol red, S. enterica was grown in Bismuth sulfite agar, $S$. aureus was grown in Staphylococcus selective Agar (CM 310) and E. oliO157:H7 was grown in MacConkey agar obtained from Beijing Land Bridge Technology co., LTD, China. Prior to extraction DNA, a single colony from each strain media was selected and inoculums into tryptic soy broth (TSB) and then incubated for overnight at $37^{\circ} \mathrm{C}$ or until the early stationary phase was reached, followed by deferent methods of extraction, and extraction was performed on $0.5,1$ and $1.5 \mathrm{ml}$ respectively.

\subsubsection{Extraction by Kit}

An overnight culture were centrifuged at $12,000 \mathrm{rpm}$ for $10 \mathrm{~min}$ at $4^{\circ} \mathrm{C}$ to pellet the cells, The supernatant was discarded and the pellet was treatment according to gram negative or positive bacteria to make a next steps, which were subjected to DNA extraction using TaKaRaMiniBEST Bacterial Genomic DNA extraction kit (Dalian, China) according to the manufacturer's instructions.

\subsubsection{Physical Method}

DNA samples extracted using physical method (the simplest way of extract) was carried out according to the [17] with slight modification. The steps of the procedure are described below, the overnight culture pelted by centrifugation $13000 \mathrm{rpm}$ to $4 \mathrm{~min}$. Supernatants were discarded without disturbing the DNA pellet, and the resulting cell pellet was resuspended in $1 \mathrm{ml}$ of ethanol and vortex at the highest speed. Incubate $10 \mathrm{~min}$ at room temperature. Samples were then centrifuged at 13,000 rpm for $5 \mathrm{~min}$ at $4^{\circ} \mathrm{C}$, and then samples were followed by resuspended in PBS buffer for washing. Pellet DNA by centrifugation at $13000 \mathrm{rpm}$ for $4 \mathrm{~min}$. The DNA pellets were resuspended in sterile TE buffer.

\subsubsection{Boiling Methods}

The rapid boiling method performed according to $[18,19]$ with slight modified. In brief, $0.5,1$ and $1.5 \mathrm{ml}$ of each overnight bacterial culture was centrifuged at 13,000 rpm for 5 min at $4{ }^{\circ} \mathrm{C}$ and the supernatant was carefully removed and the pellet was suspended in $500 \mu$ of sterile distilled water. The sample was then boiling for $15 \mathrm{~min}$ in a water bath and immediately cooled at $-20^{\circ} \mathrm{C}$ for $10 \mathrm{~min}$ prior to centrifugation at $13,000 \mathrm{rpm}$ for $5 \mathrm{~min}$ at $4^{\circ} \mathrm{C}$, and supernatant containing genomic DNA transfer in new tube and it was used for subsequent PCR amplification.

\subsubsection{Phenol/Ethanol Extraction}

It used according to $[13,20,21]$, with slight modify. Briefly, After incubation the culture for overnight, the culture was transferred into eppendorf tube and centrifuged at 13000 rpm to $10 \mathrm{~min}$ at $4^{\circ} \mathrm{C}$, and then discard supernatant and suspend pellet in $500 \mu \mathrm{TE}$ buffer, especially in procedures involving DNA and add $10 \mu \mathrm{l}$ lysozyme to broke down the bacteria that damage bacterial cell walls by catalyzing hydrolysis especially gram-positive bacteria, and incubate in ice for $5 \mathrm{~min}$. It was added $25 \mu \mathrm{l}$ proteinase $\mathrm{K}$, the enzyme digests proteins preferentially after hydrophobic amino acids and remove contamination from preparations of nucleic acid, and incubate at $55^{\circ} \mathrm{C}$, and after $10 \mathrm{~min}$ sodium dodecyl sulfate (SDS) $20 \%$ was added and incubate for $1 \mathrm{~h}$ at $55^{\circ} \mathrm{C}$, followed by add chloroform-phenol and incubate for $5 \mathrm{~min}$ to $45^{\circ} \mathrm{C}$, followed by a decrease the temperature for $5 \mathrm{~min}$ at room temperature. Samples were then centrifuged at 13000 rpm for $10 \mathrm{~min}$. It was transferred upper aqueous phases extracted (DNA) supernatant to new tube. Samples then received the addition of $95 \%$ ethanol and sodium acetate precipitated, followed by vortex and centrifuge at13000 rpm, the supernatant was discarded and the remaining pellet was washed in $70 \%$ ethanol (chilled at $-20^{\circ} \mathrm{C}$ ) invert $2-3$ times and centrifuge at $13000 \mathrm{rpm}$. The ethanol was carefully removed and dry pellet on air-dry for $20 \mathrm{~min}$ or until no ethanol by left with the tube open at room temperature to evaporate all residuals of ethanol, The DNA pellets resusspend in TE buffer and incubated at $37^{\circ} \mathrm{C}$ for $10 \mathrm{~min}$, and stored at -20 . Deionised water and buffers should be autoclaved prior to use.

\subsection{Extraction Form Real Sample (Beef)}

According to [22], with slight modification. Briefly, beef meat was purchased from a supermarket in Wuxi, China. Beef meat was cut to small pace each pace $10 \mathrm{~g}$ followed by sterilized by UV. Strains used for artificial contamination of beef were a Gram positive $S$. aureus and Gram negative $E$. coli $\mathrm{O} 157: \mathrm{H} 7$, S. enteric and A. hydrophila. The strains were grown aerobically at $37^{\circ} \mathrm{C}$ for overnight in TSB medium. The culture was diluted to a turbidity equivalent to the 0.5 McFarland Standards. Followed by artificial contaminate of beef sample, the inoculation was performed by spreading 100 $\mu l$ onto the surface of the beef with a Pasteur pipette in sterile Petri dishes containing beef. Controls consisted of uninoculated samples treated identically to the inoculated ones. The contaminated beef samples were allowed to incubate $4^{\circ} \mathrm{C}$ for $4 \mathrm{~h}$ and then of contaminated sample were used for DNA extraction from samples it was homogenized in a stomacher tube with $90 \mathrm{ml}$ of saline and placed in a sterile $2 \mathrm{~mL}$ micro centrifuge tube for DNA extraction. The preparations were peptone water, followed by agitation for 30 min at room temperature. The samples were incubated for overnight at $37^{\circ} \mathrm{C}$. After overnight culture, a $0.5,1$ and 1.5 $\mathrm{mL}$ portions of rinse fluid was removed from each bottle subjected to DNA extraction using different methods, and the PCR products were checked as above.

\subsection{Oliegonuclutide and PCR}

The oligonucleotide primers were designed in our previous study using the NCBI (http://www.ncbi.nlm.nih.gov/) and Sigma Aldrich website (http://www.sigmagenosys. com/calc/DNACalc.asp). All oligonucleotides used in this study were synthesized by (TaKaRa, Dalian, china), and listed in table 1. All PCR amplification reactions were carried out in a final volume of $25 \mu \mathrm{l}$ contained: $\mathrm{ddH}_{2} \mathrm{O}$, reverse and forward primer, dNTP, PCR buffer, Taq and target DNA. 
PCR amplification was performed in bio-Radthermocycle, PCR was carried out using the following protocol; initial denaturation for $3 \mathrm{~min}, 94^{\circ} \mathrm{C}$, followed by 30 cycles of denaturation at $94^{\circ} \mathrm{C}$ for $30 \mathrm{~s}$, primer annealing $(44,45,46$ and $53)^{\circ} \mathrm{C}$ for S. aureus, Salmonella, E.coliO157:H7 and $A$. hydrophylla, respectively, and then extension at $72^{\circ} \mathrm{C}$ for $60 \mathrm{~s}$. A final extension at $72^{\circ} \mathrm{C}$ for $5 \mathrm{~min}$ was performed, and finally the hold at $4^{\circ} \mathrm{C}$.

Table 1. Primer pairs using to amplified target DNA.

\begin{tabular}{|c|c|c|c|c|c|}
\hline Target & Gram & Oligonucleotide & Sequence(5'-3') & Length (bp) & Reference \\
\hline E. coli $\mathrm{O} 157: \mathrm{H} 7$ & Negative & $\begin{array}{l}\text { Forward } \\
\text { Reverse }\end{array}$ & $\begin{array}{l}5^{`} \text {-GATAAATCGCCATTCG-3`' } \\
5^{`} \text {-GTCACAGTAACAAACC-3` }\end{array}$ & 16 & {$[23]$} \\
\hline Staphylococcus aureus & Positive & $\begin{array}{l}\text { Forward } \\
\text { Reverse }\end{array}$ & $\begin{array}{l}5 ` \text {-GCTATCAGTAATGTTTCG -3`} \\
5{ }^{`} \text {-GCACTATATACTGTTGGA -3 }\end{array}$ & 18 & {$[24]$} \\
\hline Salmonella enterica & Negative & $\begin{array}{l}\text { Forward } \\
\text { Reverse }\end{array}$ & $\begin{array}{l}5^{`} \text {-GCGAATAATCTCTAATAG-3 } \\
5^{`} \text {-CGTTCTTGAATATGATTG-3 }\end{array}$ & 18 & This study \\
\hline Aeromonasydrophila & Negative & $\begin{array}{l}\text { Forward } \\
\text { Reverse }\end{array}$ & $\begin{array}{l}5^{`} \text {-CCAATATGTCGGTGAAGA-3`} \\
5^{\prime} \text {-CATGTTTGAAGCTGTCAG-3` }\end{array}$ & 18 & {$[24]$} \\
\hline
\end{tabular}

\subsection{Qualityfication and Quantification of Target Bacteria}

The size and the amount of amplified DNA were verified by electrophoresis on $2 \%(\mathrm{w} / \mathrm{v})$ agarose gel and electrical power was applied. Then the samples were left to migrate for a suitable time, using Tris borate EDTA buffer (TBE). After migration, gels were stained with Andy safe. Target DNA bands were photographed under ultra violet light using the BIO-RAD Gel doc 1000, molecular imager, USA. The concentration of target DNA product was assessed using the spectrophotometer nanodrop.

\subsection{Statistical Analysis}

The results were made at least in triplicate for each sample. The quantities presented were the means and standard deviations of each method. The experimental data were analyzed using the ANOVA and Duncan's multiple range tests by the SPSS 16.0 (SPSS Inc., Chicago, USA) computer program. Unless otherwise noted in the text, a $(\mathrm{P}<$ 0.05 ) level was used where values were considered as being significantly different.

\section{Results and Discussion}

In this study, we measure a simple, rapid and efficient methods for the extraction DNA from pure culture and artificial contaminate beef samples. Gram positive bacteria are more difficult than gram negative bacteria in the extract, due to their cell walls that it makes it harder to break, and require special attention. Many methods of extracting bacterial DNA directly from the crushed mother solution, including rapid methods and commercial kits [16].

The colony morphology of the four bacteria grown on selective media after $24 \mathrm{~h}$ of incubation at $37^{\circ} \mathrm{C}$ is shown in Figure 2. S. aureus has been cited as an example for grampositive bacteria and other bacteria as an example for gramnegative. DNA extraction methods are designed to break cells and denature proteins, the cell walls and membranes it's be broken to release the DNA and other intracellular components (lysis).

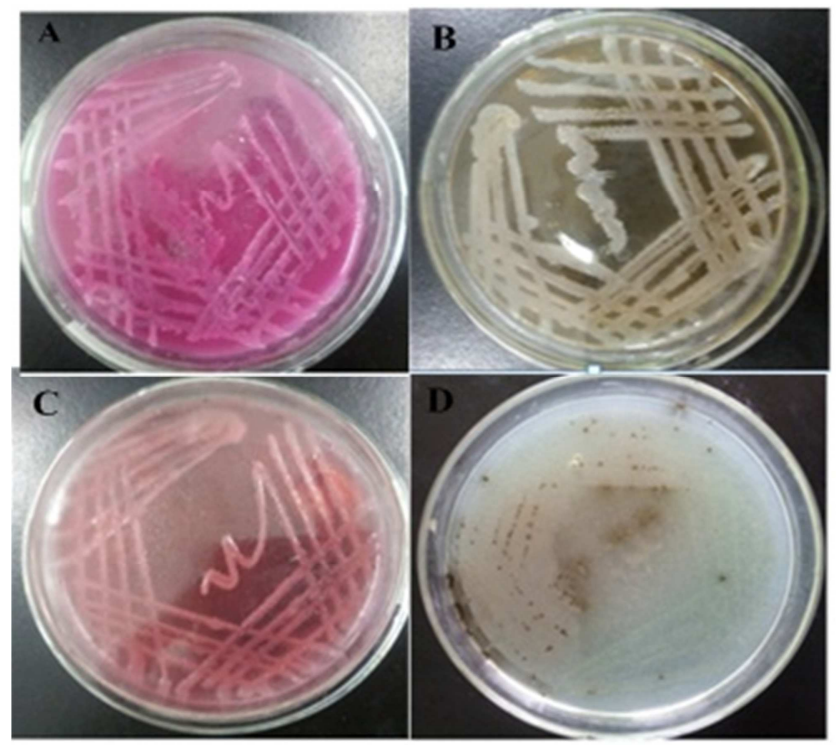

Figure 2. Colony morphology of bacteria on a selective media after incubation at $37^{\circ} \mathrm{C}$ : (A) E. coli O157:H7 (Accession number JX206444.1) on MacConkey, (B) Staphylococcus aureus (Accession number EF529607.1) on Staphylococcus selective Agar (CM 310), (C) Aeromonashidrophyla (Accession number, M84709) on Ampicilin starch agar phenol red, and (D) Salmonella enteric (Accession number GU390666) on Bismuth sulfite agar.

Nowadays, DNA extractions are the most common in molecular biology and are fundamental to life science research. Therefore, we were used with different and small amounts of culture inoculums overnight $(0.5,1.0$ and $1.5 \mathrm{ml})$ content target microorganism to study the effect of amount of PCR amplification efficiency of DNA fragments. The use of appropriate DNA extraction procedures directly on crude samples is critical for successin environmental or food samples. We found that the DNA extraction yields were increased significantly with amount of the initial culture used, it was found that there was an appreciable difference in the quantity of DNA extracted from the same method by using deferent amount. 


\subsection{DNA Extraction}

\subsubsection{Extraction by Kit}

Figure 3 shown the PCR amplification of target bacteria extracts by Kit. Extraction by kit it's a most popular method in the laboratory to extract because all materials were ready to use and followed the manufacturing procedure, but it need specific condition and some experience. Extraction is differences in cell wall structure and in adhesion properties of microorganisms together with physical, chemical and biological food characteristics affect this extraction [16].

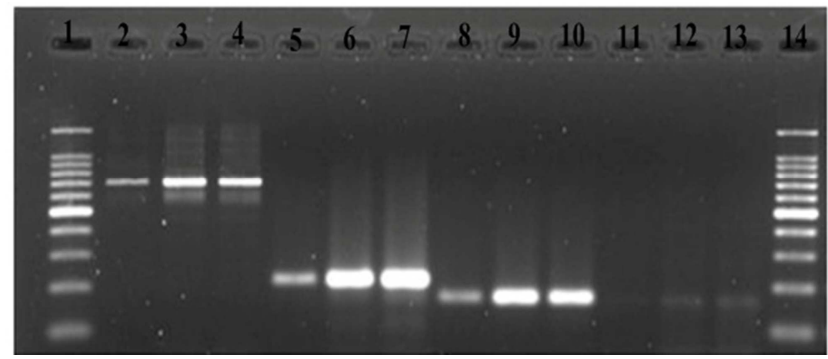

Figure 3. The result of amplification DNA templates prepared by Kit method extraction obtained from bacteria culture: Lane 1, 14. Marker 100pb, Lane 2-3-4. E. oliO157:H7, Lane 5, 6, 7. Salmonella,Lane 8, 9, 10. Aeromonashydrophella, Lane 11, 12, 13. Staphylococcus aureus.

\subsubsection{Boiling Method}

Figure 4 shown electrophoreses with boiling method. This method was performed by boiling and chilled only it doesn't need chemical material. The risk of cross contamination in boiling method associated with reusing homogenizers and vessels is unacceptable if the DNA isolated will be amplified in PCR. However, boiling method is very useful and even superior to other methods in certain applications requiring high speed, and the DNA extracted by this method was high quality and suitable for molecular analyses, such as PCR, and use of limited amounts because it is simple rapid, cheap, sensitive and doesn't need high experience.

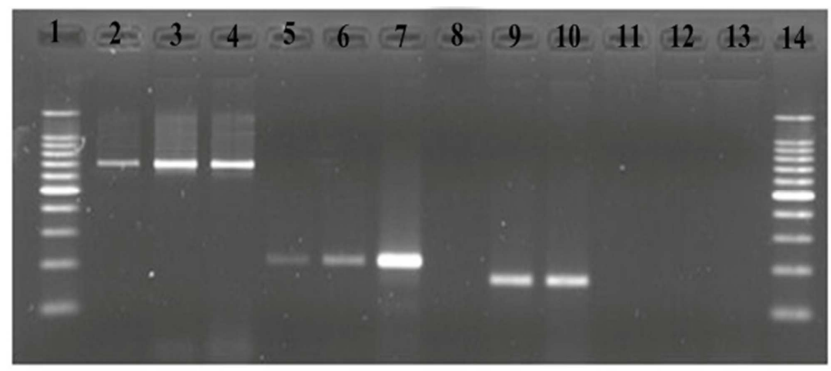

Figure 4. The result of amplification DNA templates prepared by boiling methods of extraction obtained from bacteria culture: Lane 1, 14. Marker 100pb, Lane 2, 3, 4.E. coli O157:H7, Lane 5, 6, 7. Salmonella, Lane 8, 9, 10. Aeromonashydrophella, Lane 11, 12, 13. Staphylococcus aureus.

\subsubsection{Phenol/Ethanol Method}

Figure 5 shown the Phenol/ ethanol method of different bacteria. Phenol extractions uses organic solvents that precipitate hydrophobic proteins (hydrophilic) molecules in aqueous solution. Phenol frequently used to remove proteins and denatures the proteins and facilitates the separation of the aqueous and organic phases. It's a very strong acid that causes severe burns. However, oxidized phenol can damage the nucleic acids, and precipitation with ethanol is generally used to concentrate nucleic acids, centrifugation is combined with all methods because centrifugation is a powerful purification method.

Phenol methods used SDS, it is working well for cell lysis and facilitates digestion of cells in denatured and solubilized membrane proteins. Proteinase $\mathrm{K}$ is to digest proteins including membrane proteins, Sodium acetate can be utilized to precipitate high molecular weight molecules including genomic DNA. The successive treatment with $70 \%$ ethanol allows an additional purification, or wash, of the nucleic acid from the remaining $[13,2,21,25,26]$ generally result in high efficiency DNA extractions, this material it effect the efficiently of PCR, according to [12], he limit residual concentration it should be less than SDS 0.005\%, Phenol $0.2 \%$, Ethanol $1 \%$, Isopropanol $1 \%$, Sodium acetate $5 \mathrm{mM}$, Sodium chloride $25 \mathrm{mM}$, EDTA $0.5 \mathrm{mM}$. However, the phenolic/ethanol procedure is time consuming and relates to the use of harmful organic chemicals. Moreover, this protocol was found to be laborious as it includes several high-speed centrifugation and agitation steps, and each step follow to further step so should success in the first step to move to another.

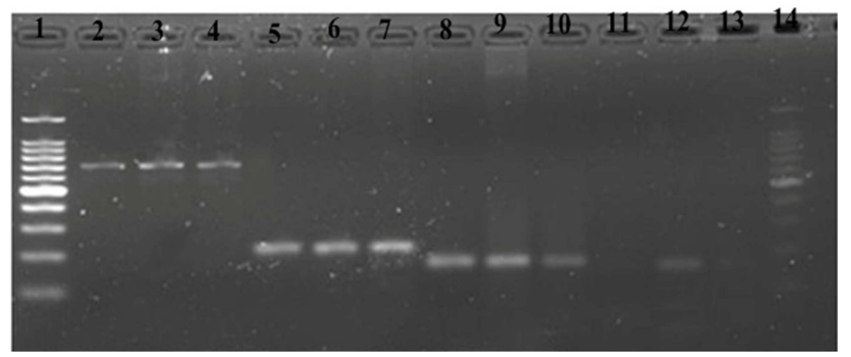

Figure 5. PCR amplification using DNA templates prepared by the Phenol/ ethanol of extraction obtained from bacteria culture: Lane 1, 14. Marker 100pb, Lane 2, 3, 4.E.coli O157:H7, Lane 5, 6, 7. Salmonella, Lane 8, 9, 10. Aeromonashydrophella, Lane 11, 12, 13. Staphylococcus aureus.

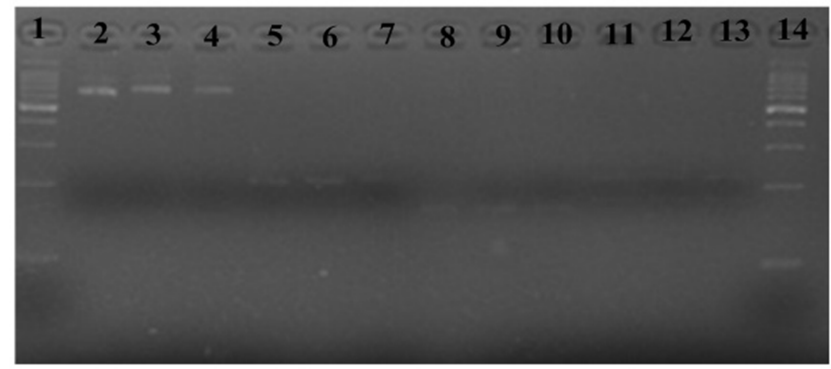

Figure 6. PCR amplification using DNA templates prepared by Physical method extraction obtained from bacteria culture: Lane 1, 14. Marker 100pb, Lane 2, 3, 4.E. coli O157:H7, Lane 5, 6, 7. Aeromonashydrophella, Lane 8, 9, 10, Staphylococcus aureus. Lane 11, 12, 13. Salmonella.

\subsubsection{Physical Methods}

Its easier method and simple steps, it's very similar to the boiling method but the difference it used without purification and used the all cells and composition of wash step, Figure 6 shown the physical method extraction for pure bacteria. 
Physical method eliminates the preparation steps required. The extraction of DNA templates is made simple and which is immediately available for the amplification of nucleic acids by PCR. The breakdown of cells by boiling and make a shock by cooling, once the cells have been broken the DNA it moves outside of cell and distribution in aqueous solutions. This method it used without washing steps so the contaminating material was not removed and sometimes can inhibit the amplification of target DNA.
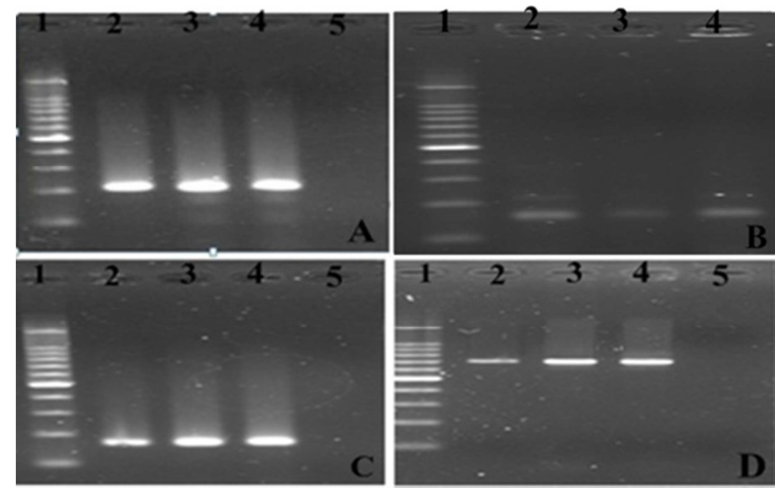

Figure 7. Agarose gel electrophoresis $2 \%$ of PCR products extracts by Kit methods from beef sample (A). Salmonella, (B). Staphylococcus aureus, (C). Aeromonashidrophyla, (D). E. coli O157:H7.
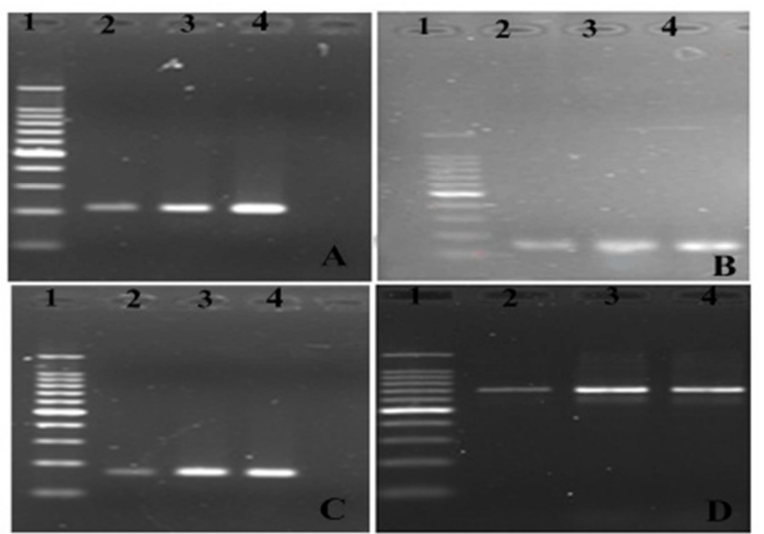

Figure 8. Agarose gel electrophoresis 2\% of PCR products extracts by Boiling methods from beef sample, (A). Salmonella, (B). Staphylococcus aureus, (C). Aeromonashidrophyla, (D). E. coli O157:H7.

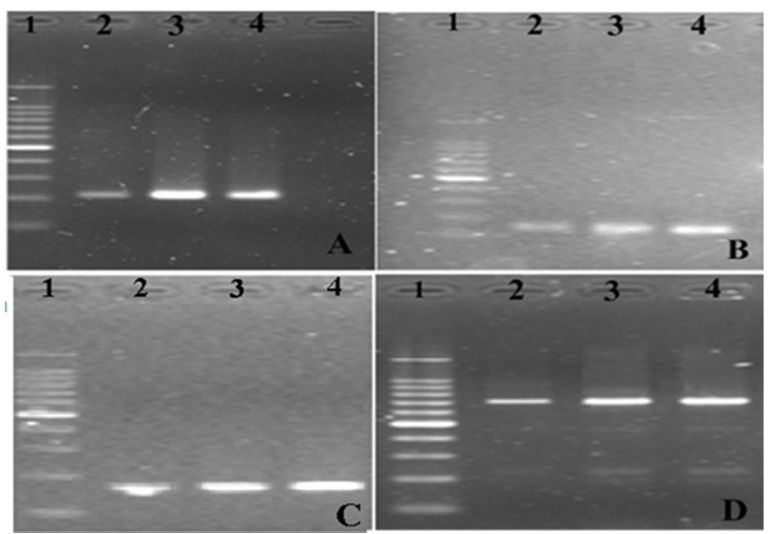

Figure 9. Agarose gel electrophoresis $2 \%$ of PCR products extracts by Phenol/ ethanol methods from beef sample, (A). Salmonella,(B). Staphylococcus aureus, (C). Aeromonashidrophyla, (D); E. coli O157:H7.

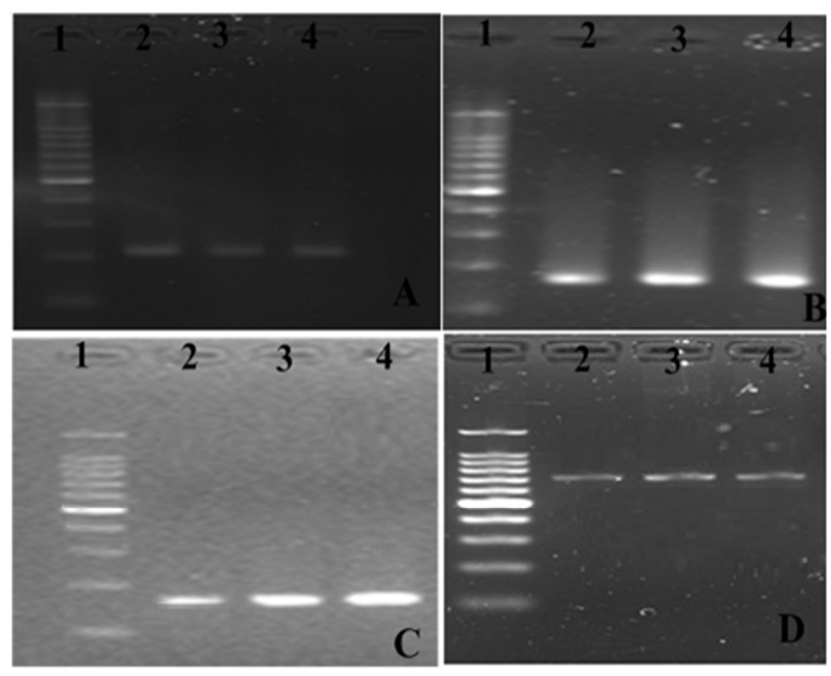

Figure 10. Agarose gel electrophoresis $2 \%$ of PCR products extracts by Physical methods from beef sample. (A). Salmonella, (B). Staphylococcus aureus, (C). Aeromonashidrophyla, (D); E. coli O157:H7.

\subsection{Artificial Contamination Samples}

Extraction results from artificial contamination of beef sample showed in Figure 7, 8, 9 and 10 for Kit, boiling, Phenol/ ethanol, physical method, respectively. Almost the methods used to extract and purify DNA from foods frequently consist of four key steps, that is, mechanical homogenization, treatment with buffers, detergents or enzymes, the application of mechanical lysis steps and the organic extraction of DNA. The comparison of quality of the DNA extraction methods for artificial contamination was performed. The four methods were tested for their efficiency using the same conditions for each other in obtaining amplifiable DNA from beef. Despite improvements in meat processing hygiene practices in recent years, the occurrence of foodborne pathogenic microorganisms is still commonplace. The absolute requirement for safe meat highlights the need for a rapid and accurate identification of these foodborne pathogens [25]. Electrophoreses and nanodrop showed that all the DNA extraction methods were successfully from artificial contamination, and different quantity depend on the initial portion used, it was measured by using nanodrop. DNA could be visualized as high band in $1.5 \mathrm{ml}$ initial extract, and minimal visual in $0.5 \mathrm{ml}$, nanodrop analyses indicated that DNA purities were slightly significant ranges compare with extractions by commercial kit. The highest DNA yields ratios between methods extraction. The DNA samples obtained by the kit and Phenol/ ethanol methods were highest DNA yields (significant extraction), while the boiling method is moderate in real samples.

\subsection{Quantity}

Means of DNA value measurement ratios for each extraction method and comparisons between methods are measured by statistical analysis SPSS software (data not shown). In order to evaluate the extraction yields of methods, measure the quantity of DNA isolated from a known amount 
of source material. Pure DNA should have a ratio of approximately 1.8 , rapid and efficient methods for the extraction of DNA specifically from bacterial cells in beef DNA with A260/280 nm ratio between 1.8 and 2.0 is considered pure [27], in recently study, the genomic DNA was high purity within a ratio of 1.5-2.

\subsection{Efficiency of the Four DNA Extraction Methods}

The boiling methods is the best because it rapid easy, not need chemical reagent and cheapest, however the phenol method it's a little complicate, use many chemical solution some it is harmful, and its need high experience, and the physical method it's not suitable because it use all the cell without filtration and its high amount of cellular contamination present in the final product, this contamination can affect procedures such as PCR and can have further negative effects on final product, use of kit more easy but also need some experience, special condition for storage, use the many materials and expensive, compare with boiling method. Low product yield was observed for the amplification of DNA extracted directly from beef samples than pure culture also it is the difference results from method to another. However, if a procedure can yield high quantities of DNA at a reduced cost, when compared to other procedures, it is most sensible to choose the protocol that yields the highest amount of extraction product.

\section{Conclusions}

The simple and rapid methods of extract DNA were measured, the study demonstrate the boiling method extremely useful, time saving high performance especially when it used in pure culture, In spite of in food samples the boiling method and phenol/ethanol method is similar, while the phenol protocol was time-consuming. The extraction by kit was the most efficient method but it more expensive and need special condition, and physical methods its use without filtration so it high contamination.

\section{References}

[1] Santos Mendonça, R. C., A. M. F. Morelli, et al. (2012). "Prediction of Escherichia coli O157: H7 adhesion and potential to form biofilm under experimental conditions." Food Control 23(2): 389-396.

[2] Kraushaar, B. and A. Fetsch (2014). "First description of PVL-positive methicillin-resistant Staphylococcus aureus (MRSA) in wild boar meat." International journal of food microbiology 186: 68-73.

[3] Chen, X., M. Gan, et al. (2014). "Development of a rapid and sensitive quantum dot-based immunochromatographic strip by double labeling PCR products for detection of Staphylococcus aureusin food." Food Control.

[4] Bruscolini, F., F. Barbieri, et al. (2014). "A multi-approach study of influence of growth temperature and nutrient deprivation in a strain of Aeromonas hydrophila." International journal of food microbiology 188: 1-10.
[5] Taskila, S., M. Tuomola, et al. (2012). "Enrichment cultivation in detection of food-borne Salmonella." Food Control 26(2): 369-377.

[6] Jenkins, M., D. Endale, et al. (2008). "Most probable number methodology for quantifying dilute concentrations and fluxes of Salmonella in surface waters." Journal of applied microbiology 104(6): 1562-1568.

[7] Control, C. f. D. and Prevention (2011). "National diabetes fact sheet: national estimates and general information on diabetes and prediabetes in the United States, 2011." Atlanta, GA: US Department of Health and Human Services, Centers for Disease Control and Prevention 201.

[8] Hsu, B.-M., K.-H. Huang, et al. (2011). "Evaluation of different analysis and identification methods for Salmonella detection in surface drinking water sources." Science of the Total Environment 409(20): 4435-4441.

[9] Budiati, T., G. Rusul, et al. (2013). "Prevalence, antibiotic resistance and plasmid profiling of Salmonella in catfish (Clarias gariepinus) and tilapia (Tilapia mossambica) obtained from wet markets and ponds in Malaysia." Aquaculture 372: 127-132.

[10] Clausen-Schaumann, H., M. Rief, et al. (2000). "Mechanical stability of single DNA molecules." Biophysical Journal 78(4): 1997-2007.

[11] Zhang, J., J. Stewart, et al. (2000). "Economical and rapid method for extracting cotton genomic DNA." J. Cotton Sci 4: 193-201.

[12] Somma, M. and M. Querci. (2004). "The Analysis of Food Samples for the Presence of Genetically Modified Organisms." Training course. World health organization regional office for Europe.

[13] Di Pietro, F., F. Ortenzi, et al. (2011). "Genomic DNA extraction from whole blood stored from 15-to 30-years at$20^{\circ} \mathrm{C}$ by rapid phenol-chloroform protocol: A useful tool for genetic epidemiology studies." Molecular and cellular probes 25(1): 44-48.

[14] McOrist, A. L., M. Jackson, et al. (2002). "A comparison of five methods for extraction of bacterial DNA from human faecal samples." Journal of microbiological methods 50(2): 131-139.

[15] Anderson, K. and S. Lebepe-Mazur (2003). "Comparison of rapid methods for the extraction of bacterial DNA from colonic and caecal lumen contents of the pig." Journal of applied microbiology 94(6): 988-993.

[16] Giacomazzi, S., F. Leroi, et al. (2005). "Comparison of three methods of DNA extraction from cold-smoked salmon and impact of physical treatments." Journal of applied microbiology 98(5): 1230-1238.

[17] Svastova, P., I. Pavlik, et al. (2002). "Rapid differentiation of Mycobacterium avium subsp. avium and Mycobacterium avium subsp. paratuberculosis by amplification of insertion element IS901." VETERINARNI MEDICINA-PRAHA47(5): 117-121.

[18] Diana, J., C. Pui, et al. (2012). "Enumeration of Salmonella spp., Salmonella Typhi and Salmonella Typhimurium in fruit juices." Int. Food Res. J 19: 51-56. 
[19] Pui, C. F., W. C. Wong, et al. (2011). "Simultaneous detection of Salmonella spp., Salmonella Typhi andSalmonella Typhimurium in sliced fruits using multiplex PCR." Food Control 22(2): 337-342.

[20] Vetrone, S. A., M. C. Huarng, et al. (2012). "Detection of nonPCR amplified S. enteritidis genomic DNA from food matrices using a gold-nanoparticle DNA biosensor: a proofof-concept study." Sensors 12(8): 10487-10499.

[21] Bai, Y., M. Song, et al. (2013). "A rapid method for the detection of foodborne pathogens by extraction of a trace amount of DNA from raw milk based on amino-modified silica-coated magnetic nanoparticles and polymerase chain reaction." Analytica chimica acta 787: 93-101.

[22] Jiang, Y., F. Gao, et al. (2010). "Changes in the bacterial communities of vacuum-packaged pork during chilled storage analyzed by PCR-DGGE." Meat science 86(4): 889-895.

[23] Abdalhai, H. M, et al (2014) "Rapid and Sensitive Detection of Foodborne Pathogenic Bacteria (Staphylococcus aureus)
Using an Electrochemical DNA Genomic Biosensor and Its Application in Fresh Beef"J. Agric. Food Chem. 62, 12659-12667.

[24] Abdalhai, H. M, et al (2015) "Electrochemical Genosensor to Detect Pathogenic Bacteria (E.Goli O157:H7) as Applied in Real Food Samples (fresh beef) to Improve Food Safety and Quality Control"J. Agric. Food Chem. 63, 5017-5025.

[25] Guan, Z. P.; Jiang, Y.; Gao, F.; Zhang, L.; Zhou, G. H.; Guan, Z. J., (2013). Rapid and simultaneous analysis of five foodborne pathogenic bacteria using multiplex PCR. European Food Research and Technology, 237, 627-637.

[26] Gao, C.-y., C.-r. Tian, et al. (2014). "Phenolic composition, DNA damage protective activity and hepatoprotective effect of free phenolic extract from Sphallerocarpus gracilis seeds." International immunopharmacology 20(1): 238-247.

[27] Nicklas, J. A. and E. Buel (2003). "Quantification of DNA in forensic samples." Analytical and bioanalytical chemistry 376(8): 1160-1167. 